Article

\title{
The Analysis of Genes and Phytohormone Metabolic Pathways Associated with Leaf Shape Development in Liriodendron chinense via De Novo Transcriptome Sequencing
}

\author{
Jikai Ma ${ }^{1}$, Lingmin Wei ${ }^{1}$, Jiayu $\mathrm{Li}^{1}$ and Huogen $\mathrm{Li}^{1,2, *}$ \\ 1 College of Forestry, Nanjing Forestry University, Nanjing 210037, China; jikai0990@foxmail.com (J.M); \\ Lingminw18@sina.cn (L.W.); lijiayuhp@foxmail.com (J.L.) \\ 2 Co-Innovation Center for Sustainable Forestry in Southern China, Nanjing Forestry University, \\ Nanjing 210037, China \\ * Correspondence: hgli@njfu.edu.cn; Tel.: +86-025-8542-8731
}

Received: 18 September 2018; Accepted: 16 November 2018; Published: 27 November 2018

\begin{abstract}
The leaf, a photosynthetic organ that plays an indispensable role in plant development and growth, has a certain ability to adapt to the environment and exhibits tremendous diversity among angiosperms. Liriodendron chinense, an ancestral angiosperm species, is very popular in landscaping. The leaf of this species has two lobes and resembles a Qing Dynasty Chinese robe; thus, leaf shape is the most valuable ornamental trait of the tree. In this work, to determine the candidate genes associated with leaf development in L. chinense, scanning electron microscopy (SEM) was employed to distinguish the developmental stages of tender leaves. Four stages were clearly separated, and transcriptome sequencing was performed for two special leaf stages. Altogether, there were $48.23 \mathrm{G}$ clean reads in the libraries of the two leaf developmental stages, and 48,107 assembled unigenes were annotated with five databases. Among four libraries, 3118 differentially expressed genes (DEGs) were enriched in expression profiles. We selected ten DEGs associated with leaf development and validated their expression patterns via quantitative real-time PCR (qRT-PCR) assays. Most validation results were closely correlated with the RNA-sequencing data. Taken together, we examined the dynamic process of leaf development and indicated that several transcription factors and phytohormone metabolism genes may participate in leaf shape development. The transcriptome data analysis presented in this work aims to provide basic insights into the mechanisms mediating leaf development, and the results serve as a reference for the genetic breeding of ornamental traits in L. chinense.
\end{abstract}

Keywords: Liriodronden chinense; SEM; leaf development; RNA sequencing; DEGs

\section{Introduction}

Since Darwin's pioneering study, a long-standing challenge in biology has been the elucidation of the genetic basis of morphological evolution [1]. Leaf shape, a conspicuous angiosperm trait, presents enormous diversity and variability [2]. Despite this profound diversity in shape, leaf morphology is chiefly classified into simple and compound types. Both simple and compound leaves initiate from a pluripotent clustered cell of the shoot apical meristem (SAM) dome, a process followed by blade growth $[3,4]$. The margins of a blade, which can be smooth, lobed or serrated, mainly determine the shape of the leaf [5].

Previous evidence has demonstrated that leaf diversity, from the formation of the tiny SAM to lateral leaf outgrowth, is controlled by gene regulatory networks (GRNs) and signaling pathways [6] 
and there is a profusion of genes that play a central role in leaf initiation and outgrowth, including transcription factor (TF) family genes, such as KNOTTED1-LIKE HOMEOBOX (KNOX) [7-9], CUP-SHAPED COTYLEDON (CUC) [10,11], and TEOSINTE BRANCHED 1-CYCLOIDEA-PCF (TCP) [12,13], and phytohormone genes [13-15], such as PINFORMD 1(PIN1), GA20-oxidase (GA20ox) and ISOPENTENYL TRANSFERASE 7 (IPT7). Beginning with the development of the leaf primordium, class I KNOX genes can regulate gibberellin (GA) and cytokinin (CK) biosynthesis, two phytohormone pathways that influence leaf initiation in the SAM [16,17]; this regulation is essential for SAM maintenance $[8,18]$. In tobacco, NTH15 encoding the KNOX protein directly suppressed NTC12, a gene encoding a GA 20-oxidase enzyme, resulting in leaf morphological changes due to decreased levels of bioactive GA in the SAM [19]. Accordingly, KNOX gene expression levels have an effect on leaf shape, and it has been reported that the overexpression of BREVIPEDICELLUS (BP/KNAT1), a class I KNOX family gene, causes smooth leaves to become deeply lobed leaves in Arabidopsis [20]. Additionally, in transgenic strawberry, repressing or overexpressing FaKNOX1 resulted in a conspicuous variation in leaf morphology [7].

In the past two decades, RNA-sequencing technology has emerged as a powerful tool to determine differentially expressed genes (DEGs) and the phytohormone signal transduction pathways in leaf development. For example, in Gevuina avellana, by using Illumina RNA-sequencing with large-scale transcriptome analysis, the DEGs of leaf primordia genes at different heteroblastic stages of responses has been enriched; these genes include PIN1, Auxin Response Factor4 (ARF4) and indole-3-acetic acid9 (IAA9), which regulate developmental programs controlled by hormones [21]. Moreover, in Betula pendula, in a comparison of the leaf transcriptome profiles between smooth and serrated leaves, a mass of DEGs were clustered, and the results showed impacts of these DEGs on leaf morphologic variation [22]. In addition, in an analysis of transcriptome data among domesticated tomato (Solanum lycopersicum) and two wild tomato relatives at four leaf developmental stages, a GRN for leaf development was identified. The results indicated the evolutionary transcriptomes and gene networks involved in leaf development and then characterized $B O P$, a $K N O X$ family gene that participates in the establishment of leaf morphology and fruit maturity of tomato and repeatedly acts in leaf shape formation [1]. In summary, RNA-sequencing technology provides an approach that is applicable to deepening the understanding of organ development in plants.

As a versatile tree species, Liriodendron chinense is widespread in southern China and northern Vietnam [23]. On the one hand, this species is an excellent timber tree that is used to manufacture high-grade furniture. On the other hand, as a well-known tree in China, L. chinense is a popular ornamental plant in landscapes and courtyards. At present, the genus of Liriodendron contains only two species in nature: L. chinense and Liriodendron tulipifera. Moreover, L. tulipifera is the dominant species in North America, while its relative, L. chinense, is an endangered species that plays a critical role in phylogenetic studies of angiosperm in Eastern Asia. Usually, the leaves of the Liriodendron genus have two deep lobes on the leaf margin, which is the most valuable ornamental trait of the leaf and the trait that most differentiates L. chinense from L. tulipifera. In most cases, the L. chinense leaf has one deep lobe on each side, while there are 2-3 lobes on each side of the leaf in L. tulipifera [24]. Thus, the $L$. chinense leaf is an important representative material for the study of leaf shape development. Although many crucial genes regulating leaf shape have been well identified in a few angiosperms, such as Arabidopsis (Arabidopsis thaliana), tobacco (Nicotiana tabacum), maize (Zea mays), and tomato (S. lycopersicum), genes mediating leaf development in L. chinense remain unknown, with limited available genomic information. In this study, scanning electron microscopy (SEM) was employed to screen all the $L$. chinense leaves within a bud. Then, we obtained the transcriptomes for two stages of leaf development, conducted a further investigation of potential hormone signaling pathways, and validated the expression pattern of genes with respect to leaf developmental stages. Our findings not only present a potential genetic mechanism of leaf shape formation but also may provide a reference for ornamental breeding in L. chinense. 


\section{Materials and Methods}

\subsection{Plant Materials}

The samples were collected from Xiashu, Jurong County, Jiangsu Province, China $\left(119^{\circ} 13^{\prime} 20^{\prime \prime} \mathrm{E}\right.$, $32^{\circ} 7^{\prime} 8^{\prime \prime} \mathrm{N}$ ), where 12 provenances of L. chinense from southern China were cultivated in 1994. In July, we sampled buds from the branches of the trees with a provenance of Wuyi Mountain, Fujian Province, China. Then, we examined the growth of dynamic tender leaves within the buds by microscopy to determine the leaf stages from which transcripts were obtained by RNA sequencing.

\subsection{Scanning Electron Microscopy (SEM) Assay}

The dissected buds were rinsed and stored overnight at $4{ }^{\circ} \mathrm{C}$ Formalin-acetic acid-alcohol (FAA) fixed liquid consisting of 38\% formalin, glacial acetic acid and 50\% alcohol. All the samples were then fixed in $1 \%$ OsO4 for $1 \mathrm{~h}$. Before isoamyl acetate treatment, the fixed samples were gradually dehydrated with ethyl alcohol for $20 \mathrm{~min}$ at different concentrations (70\%, 90\%, 95\% and 100\%). Subsequently, the samples were dried with an EMITECH K850 critical point dryer (Emitech, Ashford, UK) and coated with an Edwards E-1010 ion sputter golden coater (Hitachi, Tokyo, Japan) and observed by FEI Quanta 200 FEG MKII scanning electron microscopy (FEI, Eindhoven, Netherlands) under a suitable pressure $\left(1.94 \times 10^{-3} \mathrm{~Pa}\right)$ at $10-20 \mathrm{KV}$ of high voltage $(\mathrm{HV})$.

\subsection{Sample Preparation and RNA Extraction}

According to the morphology of the samples, there were always 4-8 tender leaves within each bud, and we classified these leaves into Stages P1, P2, P3 and P4. However, because the samples in Stage P1 were too small to collect, approximately one hundred tender leaf samples from Stages P2, P3, and $\mathrm{P} 4$ were, respectively, collected in $1.5 \mathrm{~mL}$ tubes. Then, all the leaves of each stage were sampled and rapidly immersed in RNA Keeper Tissue Stabilizer (Vayzme, Nanjing, China) at $4{ }^{\circ} \mathrm{C}$ overnight. Total RNA was extracted from tender leaves using an RNA prep pure plant kit (Tiangen, Beijing, China) following the manufacturer's instructions. The raw RNA sequencing data were deposited in the NCBI Sequence Read Archive (SRA) with the accession numbers SRR8101043, SRR8101042, SRR8101041 and SRR8101040.

\section{4. cDNA Library Construction, RNA Sequencing and Assembly}

In total, approximately $1 \mu \mathrm{g}$ of qualified RNA per sample, with two biological replicates, was used as the input material for sequencing libraries. We used the VAHTS mRNA-seq v2 Library Prep Kit for Illumina (Vayzme, Nanjing, China) to construct four libraries: LcP2-1, LcP2-2, LcP7-1 and LcP7-2. Next, all raw data were obtained from the libraries via sequencing on an Illumina Hiseq X10 platform, which generated 150-bp paired-end reads. To obtain clean reads, the raw reads were cleaned by removing reads with adapter, ploy $\mathrm{N}$ and low-quality reads using SeqPrep (https: //github.com/jstjohn/SeqPrep). The assembly was based on the clean data with high-quality analyses by using Trinity2.0 [25].

The mapped reads of each sample were assembled using Cufflinks (v2.2.1) [26] with a referencebased approach. We set Cufflinks in a probabilistic model, which provides a maximum likelihood explanation of the expression data in a given locus, to simultaneously assemble and quantify the expression patterns of a minimal set of isoforms. Then, to merge the assemblies of the samples, Cuffmerge was used to produce a master transcriptome, which was compared to known transcripts by Cuffcompare.

\subsection{Identification of Differentially Expressed Genes (DEGs)}

Cuffdiff (v2.2.1) provides statistical routines for determining differential expression in digital transcript or gene expression datasets using a model based on a negative binomial distribution. 
Transcripts or genes with corrected $p$ values less than 0.05 and an absolute value of log2 (fold change) $<1$ were considered significantly differentially expressed.

\subsection{Gene Ontology (GO) and KEGG Enrichment}

The Gene Ontology (GO) enrichment analysis of DEGs was implemented with a Perl module (GO::TermFinder) $[27,28]$. GO terms with corrected $p$ values less than 0.05 were regarded as significantly enriched among the DEGs. R functions (phyper and $q$ value) were used to test for the statistical enrichment of the DEGs among the KEGG pathways. KEGG pathways with corrected $p$ values less than 0.05 were considered significantly enriched among the DEGs.

\subsection{Quantitative Real-Time PCR ( $q R T-P C R)$ Validation}

To validate the transcriptome data profiles, ten DEGs with respect to leaf development were selected, and their expression patterns were identified via quantitative real-time PCR (qRT-PCR) with three biological replicates. Total RNA was extracted from the P2, P3 and P4 samples. Then, $300 \mathrm{ng}$ of total RNA was reverse transcribed in a $20 \mu \mathrm{L}$ reaction containing $5 \times$ PrimeScript RT Master Mix for Real time (TaKaRa, Shiga, Japan). All specific primers were 18-25 bp and generated 80-250 bp PCR products, and the Tm ranged from 58 to $60^{\circ} \mathrm{C}$. The primers are listed in Table S1. A reference housekeeping gene ( $\beta$-Actin) was used for normalization. According to the manufacturer's protocol, the reaction mixture was at a final volume of $20 \mu \mathrm{L}$ consisting of $2 \mu \mathrm{L}$ cDNA (diluted five times), $10 \mu \mathrm{L}$ SYBR Premix Ex Taq $(2 \times), 0.8 \mu \mathrm{L}$ each specific primer $(10 \mathrm{mM}), 0.4 \mu \mathrm{L}$ ROX Reference Dye II $(50 \times)$, and $6.8 \mu \mathrm{L}$ $\mathrm{ddH} 2 \mathrm{O}$ (TaKaRa, Shiga, Japan). The thermal-cycler program was as follows: $60 \mathrm{~s}$ at $95^{\circ} \mathrm{C}$ for the initial denaturation, followed by 40 cycles of $15 \mathrm{~s}$ at $95^{\circ} \mathrm{C}$ and $60 \mathrm{~s}$ at $60^{\circ} \mathrm{C}$, and $30 \mathrm{~s}$ at $60^{\circ} \mathrm{C}$ for annealing.

\section{Results}

\subsection{Dynamic Development of Leaves in L. chinense}

To determine where and when leaf organs arise, all leaves within a bud were sampled and screened. According to the developmental morphology of the samples, the leaves within a bud can be separated into four stages: P1, P2, P3 and P4. Likewise, we considered that the leaf developmental process includes three pivotal events: initiation, outgrowth, and expansion. First, we screened a tissue-like leaf primordium at an early recognizable stage of leaf development; initiating from the flank of the SAM dome, it was approximately $50 \mu \mathrm{m}$ in size, and the SAM diameter was only approximately $100 \mu \mathrm{m}$ in the final layer of the bud at this stage (Figure 1A,B). Later, tissue with a size of 200-300 $\mu \mathrm{m}$ took the shape of a small fishhook and differentiated into the leaf blade and petiole in the second layer of the bud at developmental Stage P2 (Figure 1C). Notably, at Stage P3, we found the first lobed leaf with sculptured veins on the back of the blade in a bud (Figure 1D). At Stage P4, the leaf lobe was deeper than that at Stage P3, and the prototype of the leaf morphology was achieved (Figure 1E).

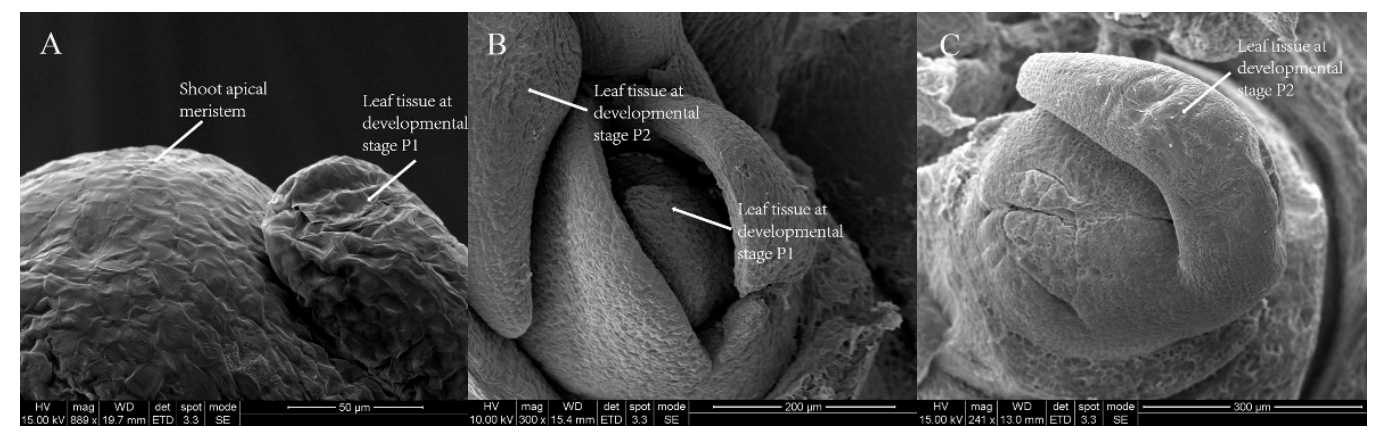

Figure 1. Cont. 

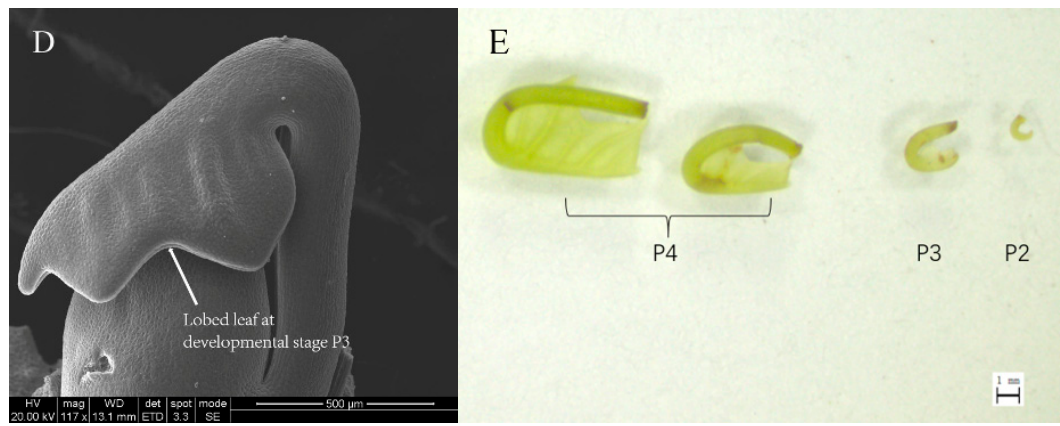

Figure 1. The dynamic development of L. chinense leaves. (A-D) Leaves in different bud layers: (A) a leaf tissue at developmental Stage P1 and shoot apical meristem (SAM) dome; (B) a leaf tissue at developmental Stage P1 and a leaf tissue at developmental Stage P2; (C) a leaf tissue taking the shape of a small fishhook at Stage P2; and (D) the first lobed leaf at Stage P3. (E) Four samples of leaves at Stages P2, P3 and P4 within a bud. Scale bars: $50 \mu \mathrm{m}$ (A); $200 \mu \mathrm{m}$ (B); $300 \mu \mathrm{m}$ (C); $500 \mu \mathrm{m}$ (D); and $1 \mathrm{~mm}$ (E). The abbreviations in the scanning electron microscopy (SEM) figures are defined in Table S4.

\subsection{Transcriptome Sequencing and De Novo Assembly}

In total, we generated 92,146,944 raw reads from Lcp2-1, 101,976,354 raw reads from Lcp7-1, 88,182,826 raw reads from Lcp2-2 and 106,177,106 raw reads from Lcp7-2 with 47.98\%, 48.84\%, 47.67\% and $48.53 \%$ GC contents, respectively (Table 1 ). After filtering the low-quality data, we obtained $385,866,426$ clean reads for de novo assembly. Furthermore, all the transcripts were clustered into 80,492 unigenes with a mean length of $1025 \mathrm{bp}$ and an N50 value of 1778 . Among all the unigenes, $11,720(14.56 \%)$ unigenes were more than $2000 \mathrm{bp}$ in length, and transcripts with lengths between 100 and $500 \mathrm{bp}$ were generated in $36,100(48.85 \%)$ of the unigenes (Table 2$)$.

Table 1. Read quality and statistics.

\begin{tabular}{|c|c|c|c|c|c|c|c|}
\hline Samples & $\begin{array}{l}\text { Total Raw } \\
\text { Reads }\end{array}$ & $\begin{array}{l}\text { Total Clean } \\
\text { Reads }\end{array}$ & $\begin{array}{c}\text { Total Clean } \\
\text { Nucleotides (nt) }\end{array}$ & $\begin{array}{c}\text { Q20 } \\
\text { Percentage }\end{array}$ & $\begin{array}{c}\text { Q30 } \\
\text { Percentage }\end{array}$ & $\begin{array}{c}\mathrm{N} \\
\text { Percentage }\end{array}$ & $\begin{array}{c}\text { GC } \\
\text { Percentage }\end{array}$ \\
\hline LcP2-1 & $92,146,944$ & $91,485,392$ & $13,722,808,800$ & $97.09 \%$ & $93.07 \%$ & $0.00 \%$ & $47.98 \%$ \\
\hline LcP2-2 & $88,182,826$ & $87,727,852$ & $13,159,177,800$ & $97.03 \%$ & $92.95 \%$ & $0.00 \%$ & $47.67 \%$ \\
\hline LcP7-2 & $106,177,106$ & $105,385,240$ & $15,807,786,000$ & $96.97 \%$ & $92.83 \%$ & $0.00 \%$ & $48.53 \%$ \\
\hline Summary & $388,483,230$ & $385,866,426$ & $57,879,963,900$ & & & & \\
\hline
\end{tabular}

Q30 indicates the nucleotides with quality values $\geq 30$, and $\mathrm{N}$ percentage is the proportion of unknown nucleotides in the clean reads. The GC percentage is the proportion of guanidine and cytosine among all the nucleotides. Lcp2-1 and Lcp2-2 are two replicates of the same stage.

Table 2. Assembly and quality of unigenes.

\begin{tabular}{ccc}
\hline Unigene Length & Total Number & Percentage \\
\hline $100-500 \mathrm{bp}$ & 36,100 & $44.85 \%$ \\
$500-1000 \mathrm{bp}$ & 15,876 & $19.72 \%$ \\
$1000-1500 \mathrm{bp}$ & 9746 & $12.11 \%$ \\
$1500-2000 \mathrm{bp}$ & 7050 & $8.76 \%$ \\
$\geq 2000 \mathrm{bp}$ & 11,720 & $14.56 \%$ \\
N50 & 1778 & \\
Mean & 1025 & \\
All unigenes & 80,492 & \\
Length of all unigenes (bp) & $82,472,451$ & \\
\hline
\end{tabular}

\subsection{Functional Annotation and Classification}

In the clusters of orthologous groups of proteins (COG) functional classification plot, 74,766 unigenes were classified into 26 groups. Moreover, the R function class (general function prediction only) contained 
approximately 5767 unigenes, and the J function class (translation, ribosomal structure and biogenesis) contained 3357 unigenes (Figure 2). All unigenes with an average length of $730 \mathrm{bp}$ were annotated according to the Nr (44,244 91.97\%), Nt (38,131 79.26\%), Swiss-Prot (28,673 59.60\%), KEGG (27,455 57.07\%), COG $(17,31836.00 \%)$ and GO $(31,66665.82 \%)$ databases (Table 3).

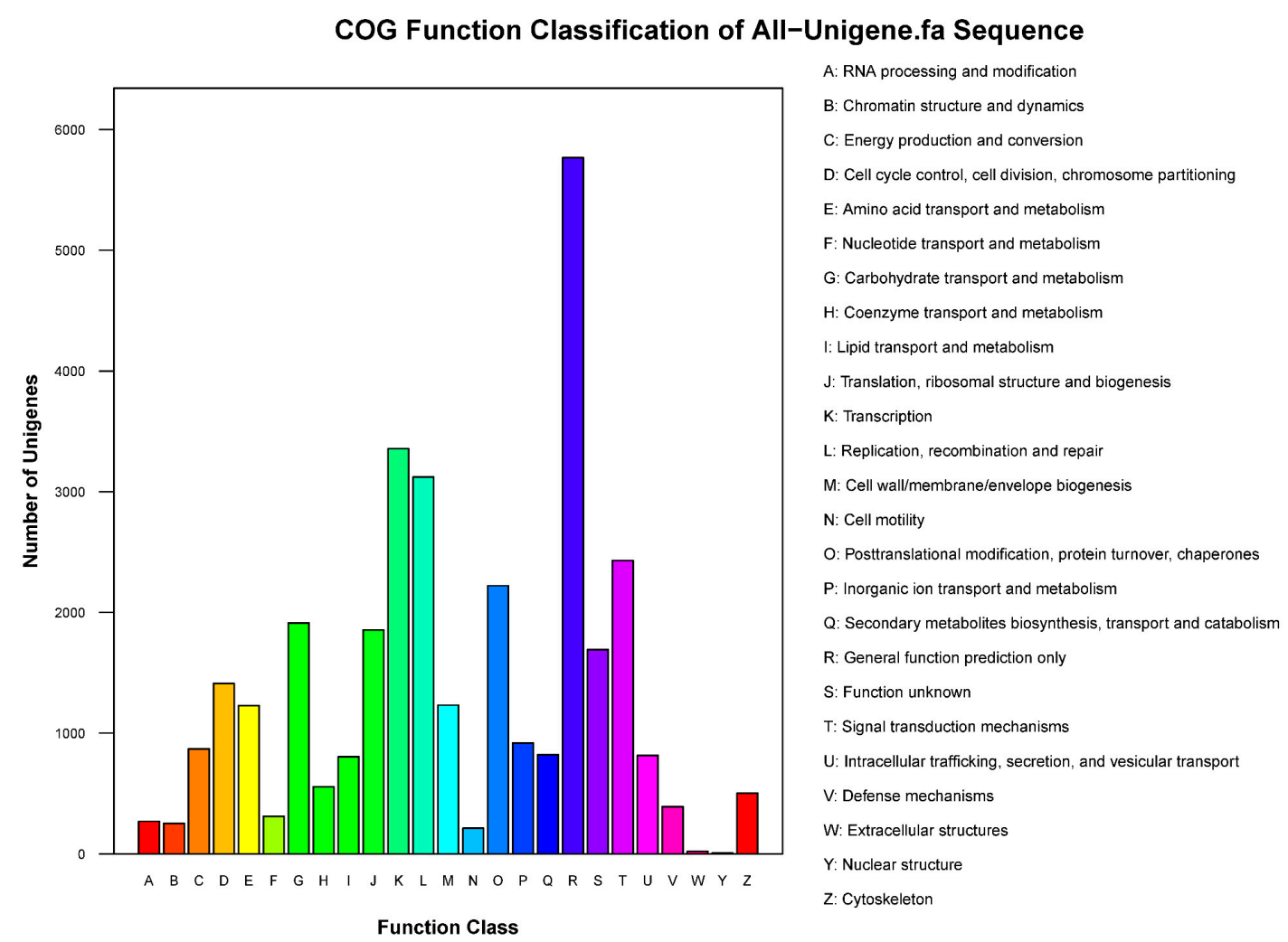

Figure 2. Clusters of orthologous groups of proteins (COG) function classification of unigenes. The vertical axis indicates the number of unigenes, and the horizontal axis indicates the function class of the unigenes.

Table 3. Unigenes annotated with six databases.

\begin{tabular}{|c|c|c|c|}
\hline Database & Total Unigenes & Annotated Unigenes & Percentage of Annotated Unigenes \\
\hline $\mathrm{Nr}$ & & 44,244 & $91.97 \%$ \\
\hline $\mathrm{Nt}$ & & 38,131 & $79.26 \%$ \\
\hline Swiss-Prot & 48107 & 28,673 & $59.60 \%$ \\
\hline KEGG & 48,107 & 27,455 & $57.07 \%$ \\
\hline COG & & 17,318 & $36.00 \%$ \\
\hline $\mathrm{GO}$ & & 31,666 & $65.82 \%$ \\
\hline
\end{tabular}

\subsection{Gene Ontology (GO) Classification of Annotated Unigenes}

Gene ontology (GO), a dynamically updated vocabulary describing the characteristics of genes and genetic products in organisms, is an international standardization of the gene function classification system. GO classification is used to classify the unigene functions based on the $\mathrm{Nr}$ annotation results. There are three main categories of GO: "molecular function", "cellular component" and "biological process". In the biological process category, "cellular process", with 19,541 unigenes, was the largest subcategory. In the cellular component category, "cell", with 24,075 unigenes, was the largest subcategory and was the most annotated process overall. Most of the "molecular function" unigenes were classified in the catalytic activity subcategory, with 16,258 unigenes, followed by the binding group subcategory, with 15,762 unigenes (Figure 3). 
All-Unigene GO Classification

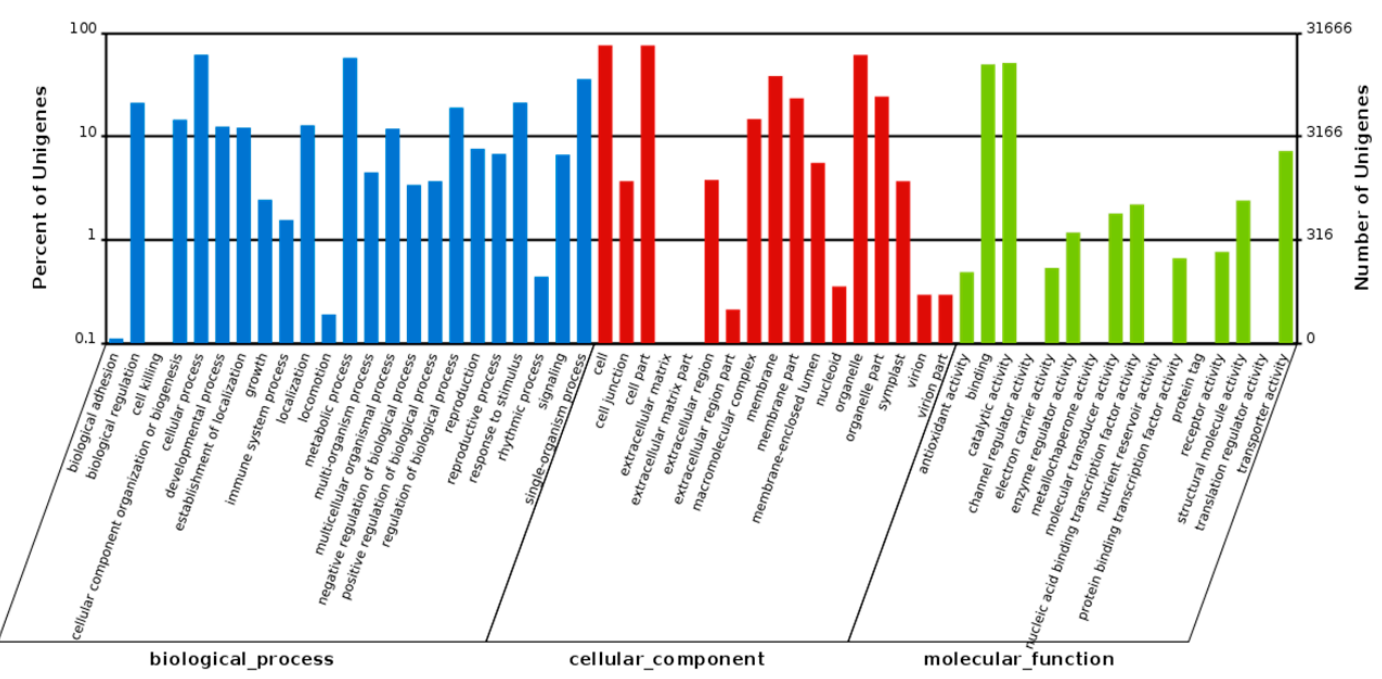

Figure 3. GO classification of unigenes. The horizontal axis shows the GO functional types, and the right-side vertical axis represents the total number of annotated unigenes, while the left-side vertical axis represents the percentage of the unigenes.

\subsection{Differentially Expressed Gene (DEG) Identification and Phytohormone Metabolic Analysis}

Setting the fold change $\geq 2.0$ and $p<0.05$, we generated 3118 DEGs and 76,815 non-differentially expressed genes. The details of the 3118 DEGs are listed in Table S3. A total of 1982 DEGs, which are indicated by red dots in Figure 4, were up-regulated. Similarly, the green dots in Figure 4 represent the 1136 DEGs that were down-regulated, and the profusion of blue dots represents genes with no differential expression (Figure 4).

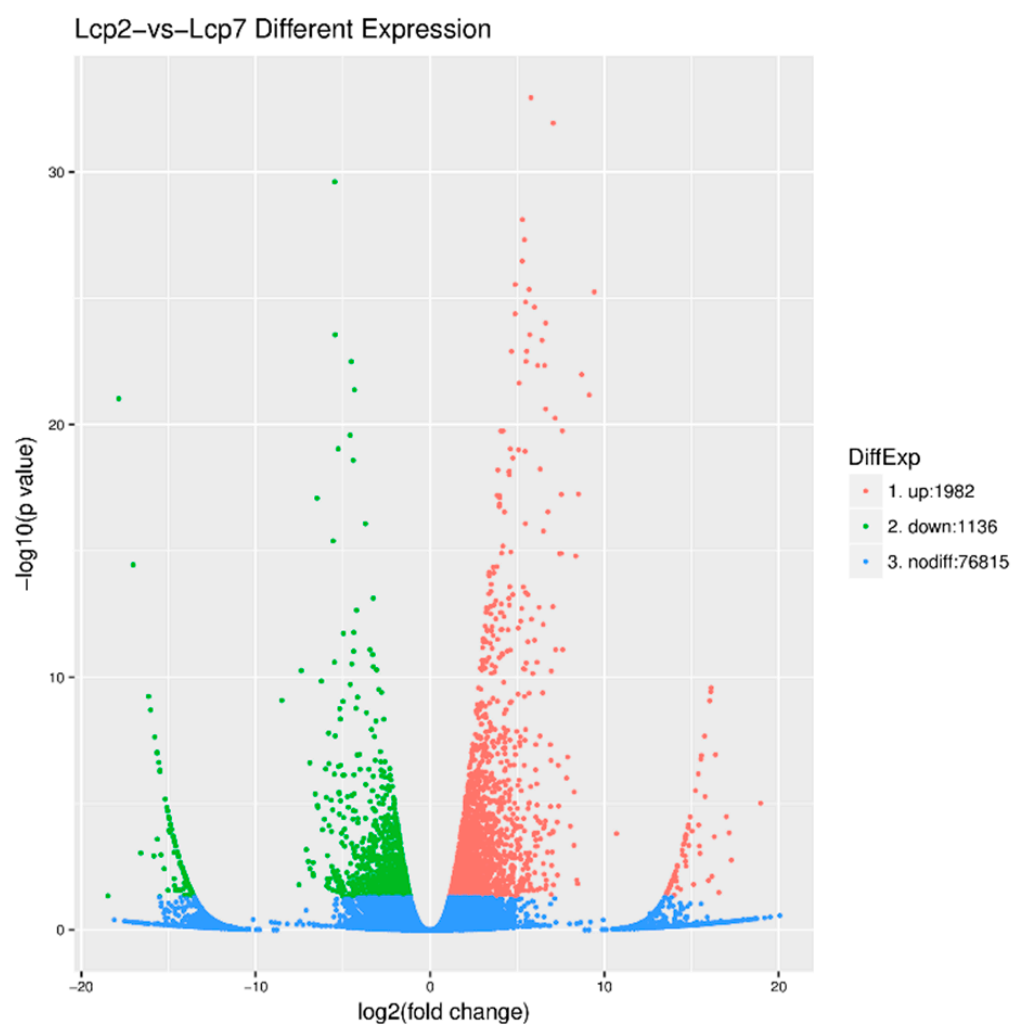

Figure 4. Differentially expressed genes (DEGs) between two leaf developmental stages. 
Based on the GO enrichment results, we plotted the top ten terms in each GO category. Apparently, "oxidoreductase activity" was enriched by the most DEGs (237 DEGs) and was the most represented term in the molecular function category. In addition, the most DEG-enriched term in the cellular category was "extracellular region", which contained 100 DEGs. There were four outstanding terms in the biological process category: "secondary metabolite process" (55), "secondary metabolite biosynthetic process" (49), "mitotic cell cycle process" (44) and "mitotic cell cycle" (44) (Figure 5).

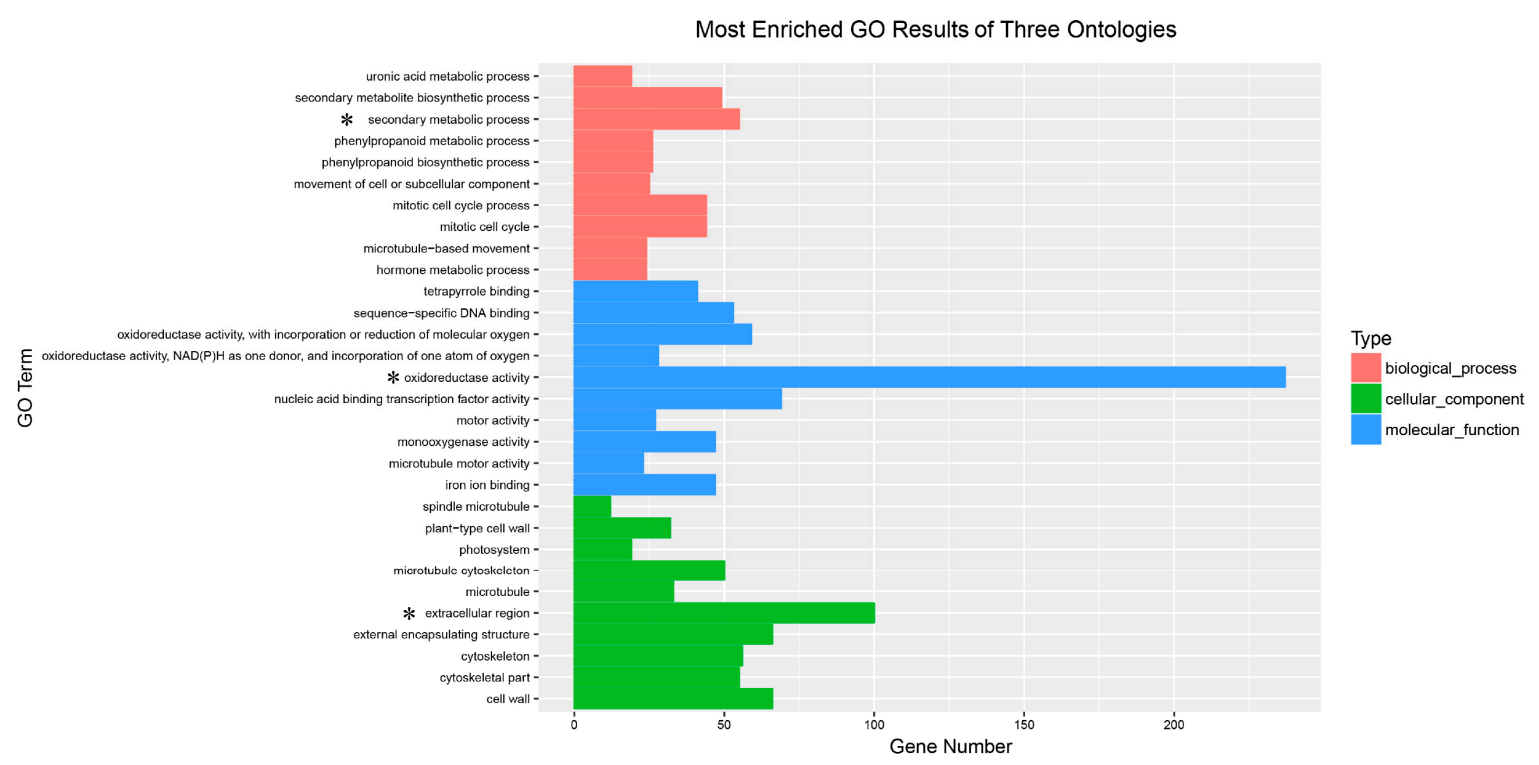

Figure 5. The most enriched GO results of three ontologies. The significant category in each of these three ontologies is marked with an asterisk.

The enrichment level of KEGG pathways was measured by the rich factor, $q$ value and enriched gene number. The plot in Figure 6 shows the twenty most significant pathways, based on the above criteria, enriched in a comparison of the two studied leaf developmental stages. To better characterize the biological functions in leaf development, the DEGs from the two studied stages of leaf development were further analyzed with the KEGG database. In this analysis, as shown in Figure 6, the red dots indicate that the metabolic pathways were enriched with more than 300 DEGs, which indicated the active metabolism of leaf development (Figure 6). However, we mainly focused on the plant hormone signal transduction pathway, which was significantly enriched by approximately 100 DEGs. These enrichments were significant and reliable, and thus, all the dots in the pathway plot are red.

Plant hormone signal transduction significantly plays a vital role in plant morphological establishment. In Figure 7, which compares two stages of leaf development, there are obviously more up-regulated genes than down-regulated genes in the seven plant hormone signal transduction pathways: auxin, cytokinin, abscisic acid, ethylene, brassinosteroid, jasmonic acid and salicylic acid. To clearly visualize differential expression in the hormone signal transduction pathways, the upregulated genes in subpathways are shown in red boxes, and the downregulated genes in subpathways are shown in green boxes. Clearly, the auxin metabolic pathway was very active, and five boxes were up-regulated, including twenty-three up-regulated genes and only one down-regulated gene in the auxin metabolic pathway. Additionally, there were seven down-regulated genes and three up-regulated genes in the CRE1 box and three up-regulated genes in the B-ARR box, which participate in the cytokinin metabolic pathway. In the gibberellin pathway, two boxes had DEGs composed of six up-regulated genes and one down-regulated gene. Those three phytohormone pathways were the most important metabolic pathways on which we mainly focused. In the abscisic acid and ethylene pathways, all DEGs were mediated in four boxes and three boxes, respectively. In the brassinosteroid pathway, four boxes had both up-regulated DEGs and down-regulated DEGs, and there was only 
one up-regulated DEG in the TCH4 box. Furthermore, there were seven up-regulated DEGs and four down-regulated DEGs in the jasmonic acid pathway. In the salicylic acid pathway, there were four up-regulated DEGs and two down-regulated DEGs in the TAG box, while only one DEG was present in the NPR1 box (Figure 7). These results showed a profusion of up-regulated genes in metabolic pathways and indicated positive phytohormone action during the leaf development process.

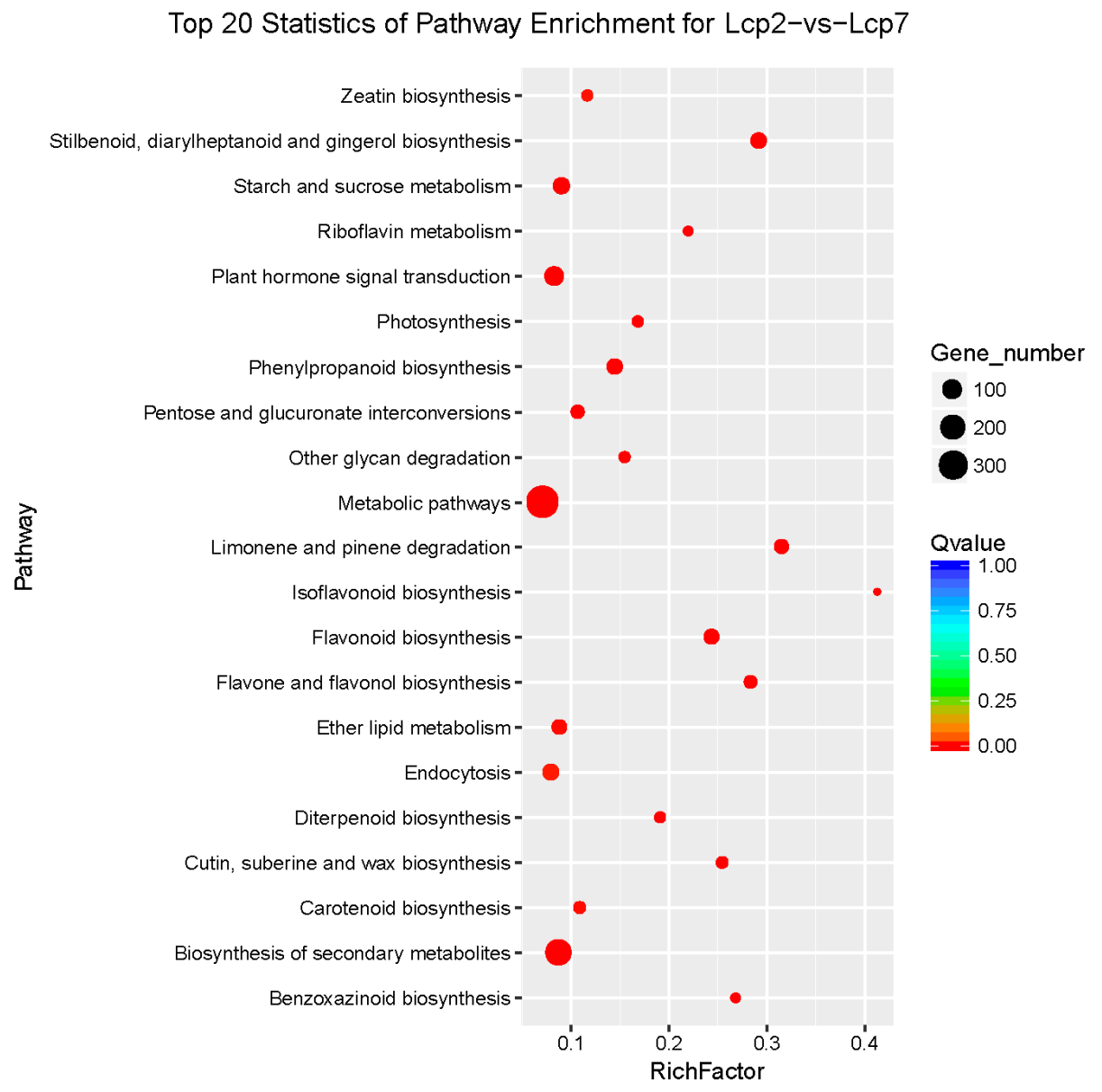

Figure 6. KEGG pathway enrichment scatter distribution. The rich factor is the ratio of DEGs in a pathway to all annotated genes in the pathway. The $q$ value is the $p$ value corrected by the multiple hypothesis correction test. Enrichments are significant when the $q$ value approaches zero. 


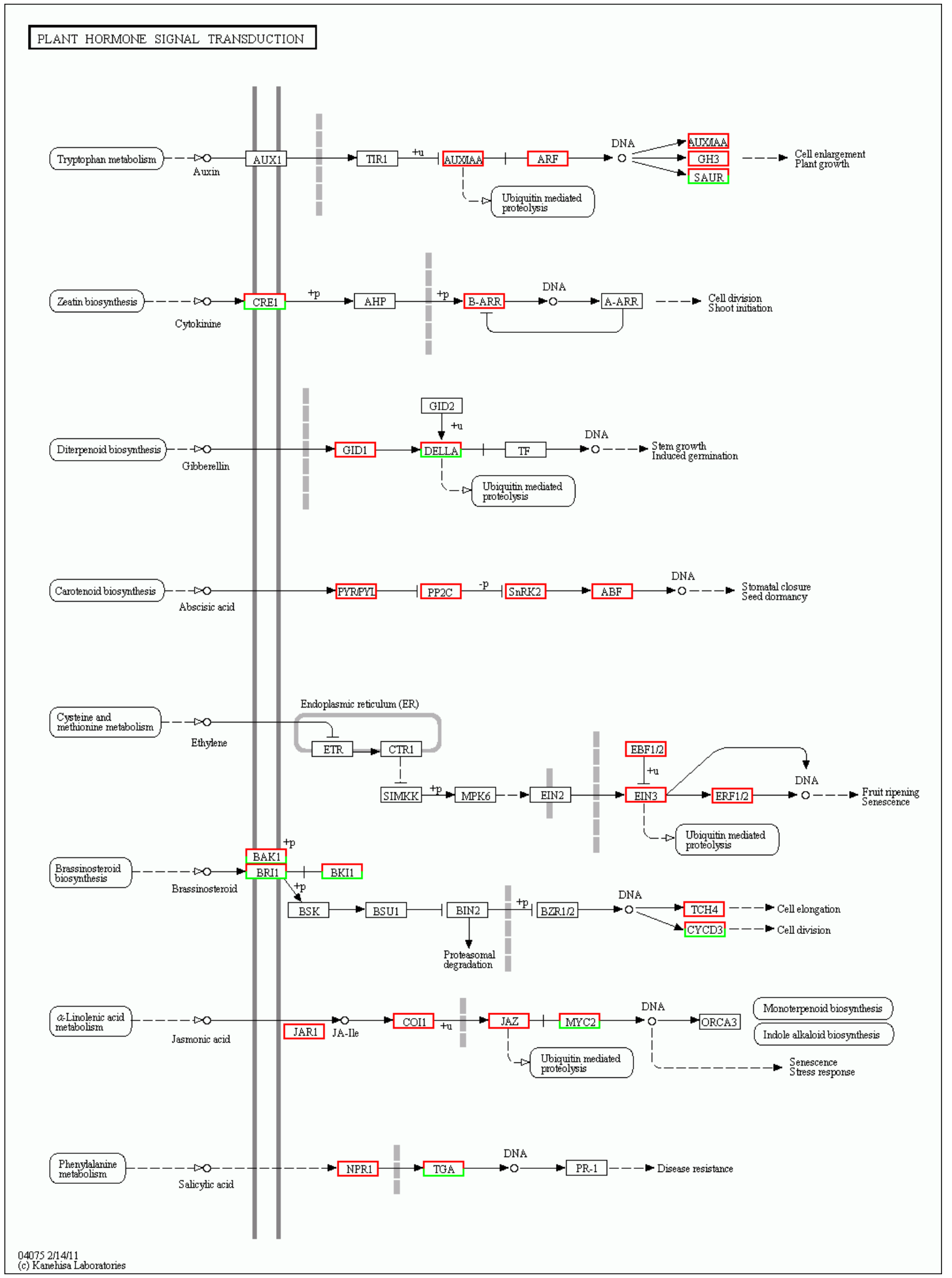

Figure 7. DEGs involved in the plant hormone signal transduction pathway. The enriched KEGG ortholog $(\mathrm{KO})$ database terms are colored according to DEG regulation: red represents up-regulation, while green means down-regulation. 


\section{6. qRT-PCR Validation of Differentially Expressed Geness (DEGs) Associated with Leaf Development}

To validate the relative expression levels from the transcript abundance estimation, we selected ten DEGs related to leaf growth regulation: GA20ox, PIN10, IAA1, HK3, KNOX1, KNOX2, KNOX3, KNOX6, CUC2, and CUC3 (Table S2). Of those, the GA20ox protein can directly repress the gibberellin level [29,30]. IAA1 and PINFORMD10 (PIN10) are genes influencing the auxin level [31]; HK3 (HISTIDINE KINASE3) mediates the cytokinin level [32]; and KNOX2, KNOX3 and KNOX6 are TFs encoding knotted-like homeobox family proteins. The expression levels of all of these DEGs were associated with transcriptome analysis. Four of the DEGs-GA20ox, PIN10, IAA1, HK3—are plant hormone signal transduction factors, and the remaining DEGs, mainly consisting of KNOTTED1-LIKE HOMEOBOX TF family genes [33,34] and CUP-SHAPED COTYLEDON TF family genes [11,35], are closely related to the regulation of leaf growth. Plant hormones have a great effect on leaf initiation and outgrowth. IAA1 and PIN10 are related to the auxin hormone metabolism pathway, but the expression of these genes exhibited different trends in this work. Indeed, PIN10 expression levels were lower in Stage P2 than in Stage P4, but IAA1 showed a trend of down-regulation during three stages. In addition, one of the GA pathway genes and one of the CK pathway genes were used to verify the reliability of the transcriptome data and showed a correlation with the transcriptome results (Figure 8). According to a previous study, class I KNOTTED1-LIKE HOMEOBOX family genes mainly express in the SAM and primordium tissue. In this work, the KNOX6 gene exhibited low expression levels at leaf developmental Stages P3 and P4 but had high expression levels at Stage P2. Furthermore, KNOX3 showed a trend of up-regulated expression during three stages. Actually, KNOX3 belongs to the class II KNOTTED1-LIKE HOMEOBOX family, and the main functions of this subfamily are barely related to the establishment of leaf morphology. The CUC3 gene exhibited a very high expression level in Stage P4 but was seldom expressed in Stages P2 and P3. Additionally, the expression levels of KNOX2 exhibited a decreasing trend while the KNOX3 gene showed an increasing expression trend (Figure 9). The expression levels of ten selected genes as measured by RNA-sequencing and qRT-PCR were correlated. Most of the points were close to the line and the $p$-value was $<0.01 ; R^{2}=0.5655$ (Figure 10). Taken together, the transcript data were reliable and reproducible; most of the qRT-PCR validation results were correlated with the DEG data.

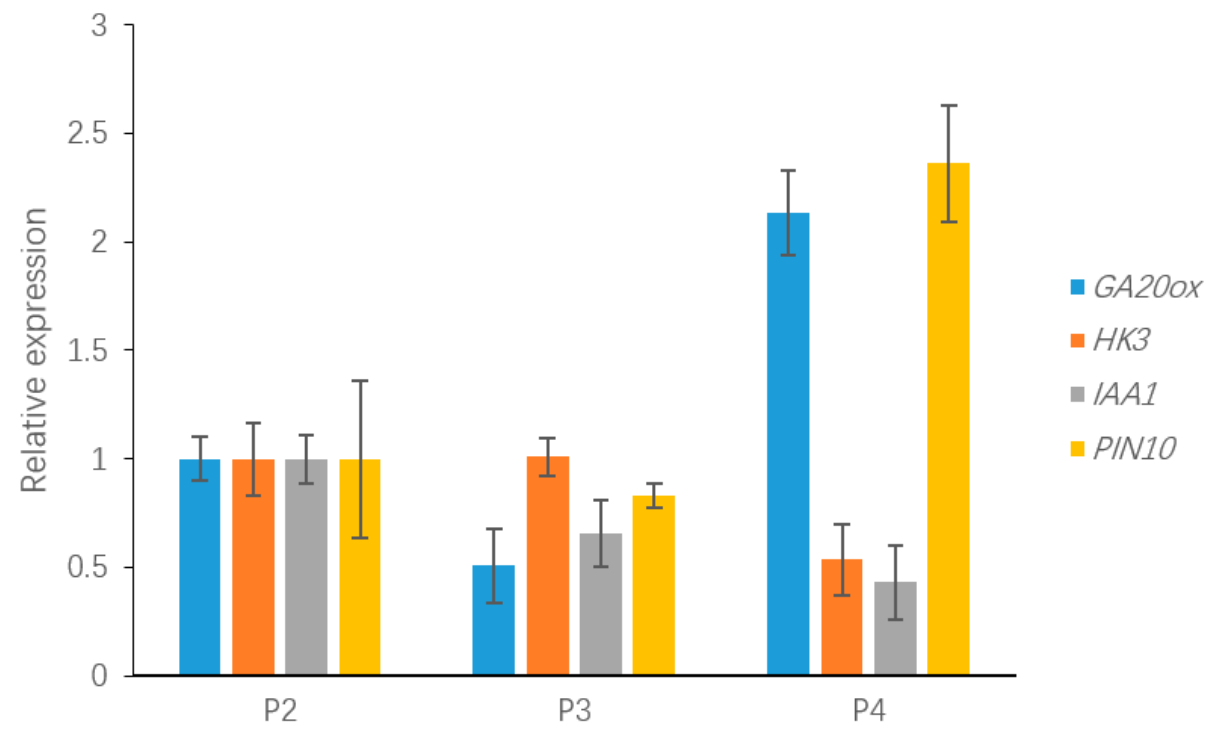

Figure 8. The expression of DEGs related to plant hormone signal transduction, including GA20ox, PIN10, IAA1 and HISTINDINE KINASE3, which may be involved in leaf development. 


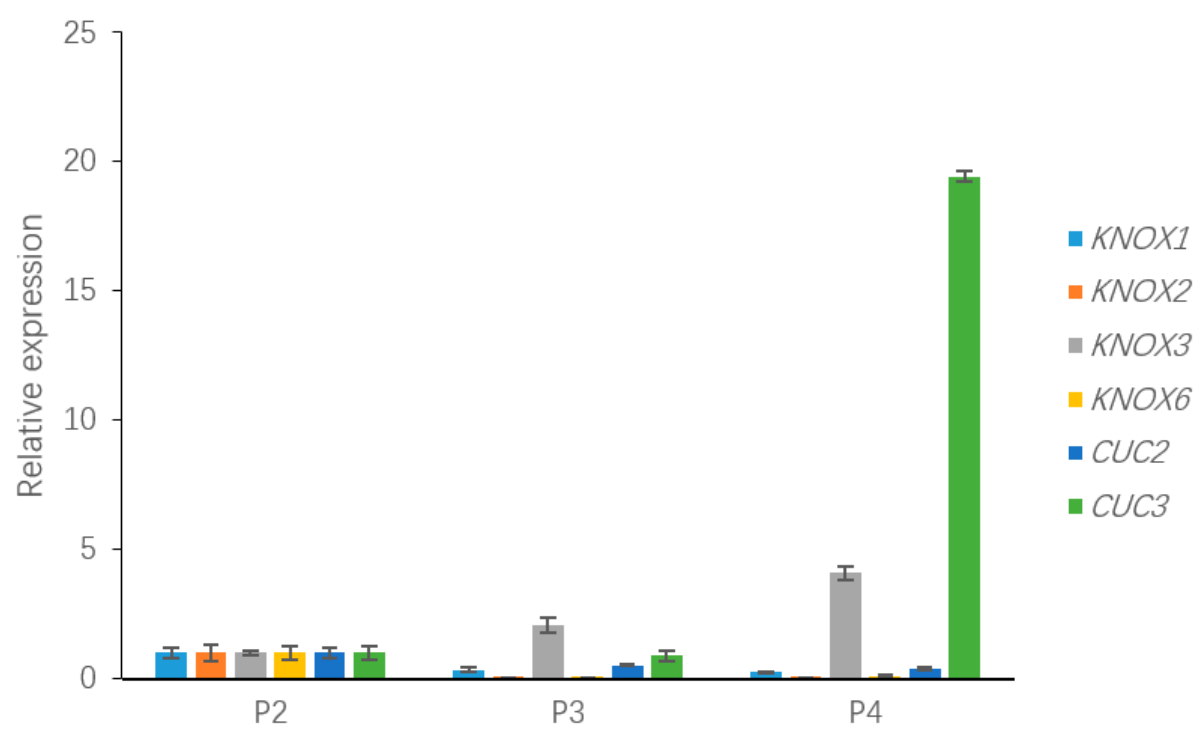

Figure 9. The expression of DEGs in the KNOTTED1-LIKE HOMEOBOX family and CUP-SHAPED COTYLEDON TF family, including KNOX1, KNOX2, KNOX3, KNOX6, CUC2, and CUC3, which may be involved in leaf development.

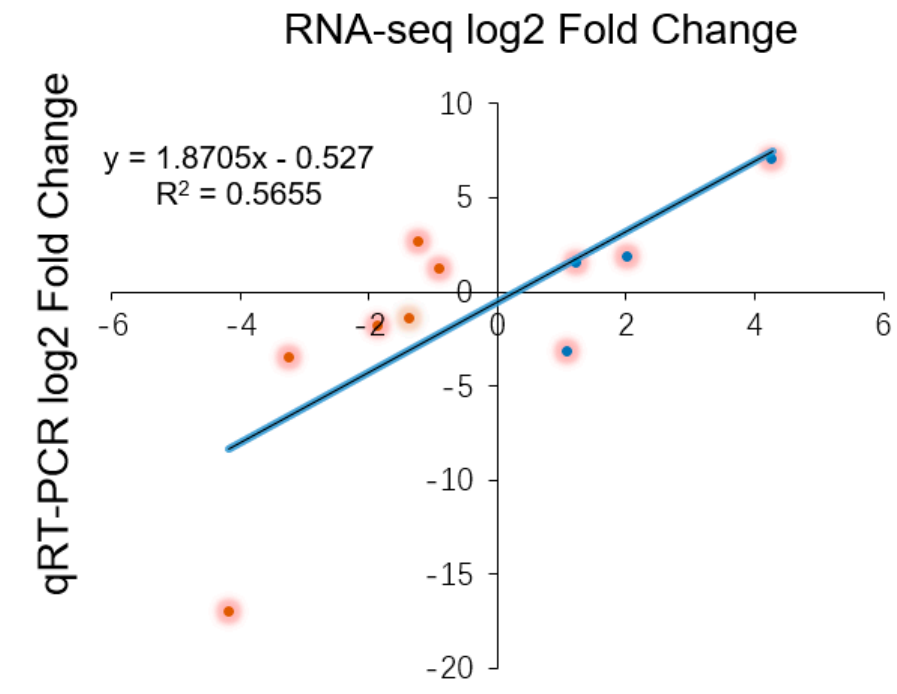

Figure 10. The logarithmic fold change values for the RNA-sequencing and qRT-PCR results are plotted along with the linear fit line to identify the correlation between two techniques $\left(R^{2}=0.5655, p<0.01\right)$.

\section{Discussion}

\subsection{Leaf Initiation and Dynamic Development}

To achieve their final shape and size, plant leaves must undergo three pivotal events: initiation, outgrowth, and expansion. Regardless of the final leaf shape, the incipient leaf initiates as a simple primordium from the SAM [36]. Once asymmetry has formed, the leaf primordium, initiated from the SAM, undergoes elongation and partitioning into a proximal petiole [5]. For this study, we aimed to examine the dynamic process of leaf development in L. chinense. Using the SEM method, we classified all leaves within a bud into Stages P1, P2, P3 and P4. In Arabidopsis, to achieve the final leaf morphology, leaf development is followed by the progression of trichomes [37], the provascular strand [38], enlarged epidermal cells [39], modified cellular morphology, and differentiating guard cells [40]. We captured the image of tissue-like leaf primordium with only $50 \mu \mathrm{m}$ size at Stage P1. After that, the tissue differentiated into leaf blade and petiole. Furthermore, the first lobed leaf, composed of a petiole, 
lamina and leaf lateral vein, arose at Stage P3. Subsequently, the morphology of the leaf steadily developed in Stage P4. Overall, since the leaf obviously differentiated into blade and petiole at Stage P2 and leaf shape was achieved at Stage P4, samples from these two special stages were analyzed with transcriptome sequencing.

\subsection{Genes Associated with Leaf Development}

Hitherto, many works have identified the genes regulating leaf shape and variation, such as CUC2/3, CIN and PIN, that have significant effects on the processes of leaf development [41]. In this work, among the 3118 identified DEGs, ten DEGs associated with leaf shape in several model plants, such as the KNOTTED1-LIKE HOMEOBOX family genes, the CUP-SHAPED COTYLEDON family genes and IAA1, GA20ox and HISTIDINE KINASE3 genes from the auxin, gibberellin and cytokinin hormone transduction signal pathways, were selected to validate the relative expression levels by qRT-PCR assays. The differential regulation and descriptions of these genes are listed in Table S2.

The expression of the "meristem" genes in the leaf primordium could affect leaf shape and size via regulating hormone gradients and possibly transport [3]. A large body of evidence suggests that the precise regulation of KNOX gene activity is crucial to the determination of organ versus meristem identity in many plant species [14]. According to the annotation results, five DEGs were annotated with the KNOTTED1-LIKE HOMEOBOX family term, and the expression levels of four of these candidate DEGs were validated. Notably, the KNOX2 gene was expressed at very low levels in Stages P3 and P4 but had a high expression level in Stage P2. A similar situation has been reported in Arabidopsis, in which the KNOX family consists of three classes: class I, class II and class III. Class I contains SHOOTMERISTEMLESS (STM), BREVIPEDICELLUS (BP/KNAT1), KNAT2 and KNAT6, four genes with specific expression in the plant meristem [42]. All of these genes have a conserved homeodomain (HD) encoding the HD protein [43]. In addition, previous studies have concentrated on the role that hormones, such as auxin, play in releasing biophysical constraints on the incipient primordium and have indicated that the final stage of leaf formation is supported by the coordination of hormonally mediated cell processes, division and differentiation [3]. According to the KEGG enrichment analysis, approximately 100 DEGs with rich factors approaching 0.1 were clustered in the plant hormone signal transduction pathway. Of these, from the gibberellin and auxin biosynthesis metabolic pathways, we obtained several key DEGs that may participate in leaf shape development. Moreover, our results also showed that the KNOX1 gene, which was mainly up-regulated in Stage P2, showed a low expression level and down-regulation in developmental Stages P3 and P4. Furthermore, the KNOX2 and KNOX6 genes showed extremely low expression patterns in developmental Stages P3 and P4. According to previous work, the NTH15 gene encoding the tobacco KNOX protein, directly binds to GTGAC, an intron sequence of NTC12 encoding GA20-oxidase, which is essential for the biosynthesis of gibberellin, resulting in a decrease in GA levels, and this decrease may influence cell proliferation and cell differentiation [19]. Coincidentally, in our validation analysis, the GA20ox gene expression level demonstrated a certain correlation with KNOX2 gene expression in Stages P2 and P3. In several plants, due to the downregulation of KNOX1 in different pathways, low cytokinin to high gibberellin levels are attained, and pathways are regulated by auxin via polar transport at the sites of leaf initiation, thereby repressing KNOX1 [44] and cytokinin signaling at specific districts [45].

Previous work investigating a wide range of lobed/serrated leaves has shown that CUC2 is a dispensable factor [11]. Several works suggest that CUC2 expression is repressed by PIN1-generated auxin maxima [46]. In addition, CUC2 is always down-regulated at the leaf margin, where PIN1 convergent polarities are expected to exhibit high auxin levels [47,48]. Our observations suggested that CUC2 expression levels were high at Stage P4, whereas PIN10, encoding an auxin efflux protein [49], synchronously showed low expression levels. CUC2 is considered to affect the early onset of leaf teeth, but CUC3 is thought to take part in sustaining leaf teeth outgrowth only at later stages [46]. However, there was no direct relationship between CUC2 and CUC3 in the validation data. Furthermore, the PIN10 expression trend did not exhibit a correlation with the IAA1 trend, even though the IAA 
family is also closely associated with the auxin hormone level [15]. Altogether, we indicated a few genes that are related to leaf development, such as the KNOX2, KNOX6 and CUC2 genes, and these findings may provide insights into the mechanisms mediating leaf development in L. chinense.

\section{Conclusions}

In summary, we classified all the developing tender leaves within a bud into Stages P1, P2, P3 and $\mathrm{P} 4$, and two special stages of leaves were analyzed by transcriptome sequencing. In this work, $385,866,426$ clean reads were assembled into 298,261 unigenes, with a mean length of $732 \mathrm{bp}$. Of these, $158,814(53.25 \%)$ unigenes were annotated to the Nr, Nt, SWISS, COG and KEGG databases, which are five publicly available protein databases with significant similarity. Moreover, we obtained 3118 DEGs, ten of which were selected as candidate DEGs. These candidate DEGs related to leaf development were validated in the four leaf stages, and most transcriptome data were closely correlated with qRT-PCR results. Consequently, these findings may provide insight into the mechanisms mediating leaf development and a reference for genetic breeding of ornamental characteristics in L. chinense.

Supplementary Materials: The following are available online at http:/ / www.mdpi.com/2073-4425/9/12/577/s1, Table S1: All the qRT-PCR primer sequences, Table S2: Annotation of candidate genes related to leaf development, Table S3: The list of DEGs, Table S4: The abbreviations in text.

Author Contributions: J.M. conducted the experiments, analyzed the data and wrote the manuscript. J.L. and L.W. participated in the sample collection and carried out the qRT-PCR assays. H.L. designed the project and revised the manuscript. All authors read and approved the final manuscript.

Funding: This research was funded by National Natural Science Foundation of China (grant numbers 31770718 and 31470660).

Acknowledgments: We are thankful for funding from National Natural Science Foundation of China (31770718 and 31470660) and the Priority Academic Program Development of Jiangsu Higher Education Institutions (PAPD).

Conflicts of Interest: The authors declare that they have no conflicts of interest.

\section{References}

1. Ichihashi, Y.; Aguilar-Martinez, J.A.; Farhi, M.; Chitwood, D.H.; Kumar, R.; Millon, L.V.; Peng, J.; Maloof, J.N.; Sinha, N.R. Evolutionary developmental transcriptomics reveals a gene network module regulating interspecific diversity in plant leaf shape. Proc. Natl. Acad. Sci. USA 2014, 111, E2616-E2621. [CrossRef] [PubMed]

2. Nicotra, A.B.; Leigh, A.; Boyce, C.K.; Jones, C.S.; Niklas, K.J.; Royer, D.L.; Tsukaya, H. The evolution and functional significance of leaf shape in the angiosperms. Func. Plant Biol. 2011, 38, 535-552. [CrossRef]

3. Kessler, S.; Sinha, N. Shaping up: The genetic control of leaf shape. Curr. Opin. Plant Biol. 2004, 7, 65-72. [CrossRef] [PubMed]

4. Barkoulas, M.; Hay, A.; Kougioumoutzi, E.; Tsiantis, M. A developmental framework for dissected leaf formation in the Arabidopsis relative Cardamine hirsuta. Nat. Genet. 2008, 40, 1136-1141. [CrossRef] [PubMed]

5. Efroni, I.; Eshed, Y.; Lifschitz, E. Morphogenesis of Simple and Compound Leaves: A Critical Review. Plant Cell 2010, 22, 1019-1032. [CrossRef] [PubMed]

6. Dkhar, J.; Pareek, A. What determines a leaf's shape? Evodevo 2014, 5, 47. [CrossRef] [PubMed]

7. Chatterjee, M.; Bermudez-Lozano, C.L.; Clancy, M.A.; Davis, T.M.; Folta, K.M. A strawberry KNOX gene regulates leaf, flower and meristem architecture. PLoS ONE 2011, 6, e24752. [CrossRef] [PubMed]

8. Tsuda, K.; Ito, Y.; Sato, Y.; Kurata, N. Positive Autoregulation of a KNOX Gene Is Essential for Shoot Apical Meristem Maintenance in Rice. Plant Cell 2011, 23, 4368-4381. [CrossRef] [PubMed]

9. Vuolo, F.; Mentink, R.A.; Hajheidari, M.; Bailey, C.D.; Filatov, D.A.; Tsiantis, M. Coupled enhancer and coding sequence evolution of a homeobox gene shaped leaf diversity. Genes Dev. 2016, 30, 2370-2375. [CrossRef] [PubMed]

10. Hibara, K.; Karim, M.R.; Takada, S.; Taoka, K.; Furutani, M.; Aida, M.; Tasaka, M. Arabidopsis CUP-SHAPED COTYLEDON3 regulates postembryonic shoot meristem and organ boundary formation. Plant Cell 2006, 18, 2946-2957. [CrossRef] [PubMed] 
11. Hasson, A.; Plessis, A.; Blein, T.; Adroher, B.; Grigg, S.; Tsiantis, M.; Boudaoud, A.; Damerval, C.; Laufs, P. Evolution and Diverse Roles of the CUP-SHAPED COTYLEDON genes in Arabidopsis Leaf development. Plant Cell 2011, 23, 54-68. [CrossRef] [PubMed]

12. Kieffer, M.; Master, V.; Waites, R.; Davies, B. TCP14 and TCP15 affect internode length and leaf shape in Arabidopsis. Plant J. 2011, 68, 147-158. [CrossRef] [PubMed]

13. Gupta, M.D.; Aggarwal, P.; Nath, U. CINCINNATA in Antirrhinum majus directly modulates genes involved in cytokinin and auxin signaling. New Phytol. 2014, 204, 901-912. [CrossRef] [PubMed]

14. Hay, A.; Kaur, H.; Phillips, A.; Hedden, P.; Hake, S. The gibberellin pathway mediates KNOTTED1-Type Homeobox function in plants with different body plans. Curr. Biol. 2002, 12, 1557-1565. [CrossRef]

15. Koenig, D.; Bayer, E.; Kang, J.; Kuhlemeier, C.; Sinha, N. Auxin patterns Solanum lycopersicum leaf morphogenesis. Development 2009, 136, 2997-3006. [CrossRef] [PubMed]

16. Jasinski, S.; Piazza, P.; Craft, J.; Hay, A.; Woolley, L.; Rieu, I.; Phillips, A.; Hedden, P.; Tsiantis, M. KNOX action in Arabidopsis is mediated by coordinate regulation of cytokinin and gibberellin activities. Curr. Biol. 2005, 15, 1560-1565. [CrossRef] [PubMed]

17. Bolduc, N.; Hake, S. The maize transcription factor KNOTTED1 directly regulates the gibberellin catabolism gene ga2ox1. Plant Cell 2009, 21, 1647-1658. [CrossRef] [PubMed]

18. Vollbrecht, E.; Reiser, L.; Hake, S. Shoot meristem size is dependent on inbred background and presence of the maize homeobox gene, knotted1. Development 2000, 127, 3161. [PubMed]

19. Sakamoto, T.; Kamiya, N.; Ueguchi-Tanaka, M.; Iwahori, S.; Matsuoka, M. KNOX homeodomain protein directly suppresses the expression of a gibberellin biosynthetic gene in the tobacco shoot apical meristem. Gene Dev. 2001, 15, 581-590. [CrossRef] [PubMed]

20. Magnani, E.; Hake, S. KNOX lost the OX: The Arabidopsis KNATM gene defines a novel class of KNOX transcriptional regulators missing the homeodomain. Plant Cell 2008, 20, 875-887. [CrossRef] [PubMed]

21. Ostria-Gallardo, E.; Ranjan, A.; Chitwood, D.H.; Kumar, R.; Townsley, B.T.; Ichihashi, Y.; Corcuera, L.J.; Sinha, N.R. Transcriptomic analysis suggests a key role for SQUAMOSA PROMOTER BINDING PROTEIN LIKE, NAC and YUCCA genes in the heteroblastic development of the temperate rainforest tree Gevuina avellana (Proteaceae). New Phytol. 2016, 210, 694-708. [CrossRef] [PubMed]

22. Mu, H.; Lin, L.; Liu, G.; Jiang, J. Transcriptomic analysis of incised leaf-shape determination in birch. Gene 2013, 531, 263-269. [CrossRef] [PubMed]

23. Jin, H.; Do, J.; Moon, D.; Noh, E.W.; Kim, W.; Kwon, M. EST analysis of functional genes associated with cell wall biosynthesis and modification in the secondary xylem of the yellow poplar (Liriodendron tulipifera) stem during early stage of tension wood formation. Planta 2011, 234, 959-977. [CrossRef] [PubMed]

24. Yang, Y.; Xu, M.; Luo, Q.; Wang, J.; Li, H. De novo transcriptome analysis of Liriodendron chinense petals and leaves by Illumina sequencing. Gene 2014, 534, 155-162. [CrossRef] [PubMed]

25. Grabherr, M.G.; Haas, B.J.; Yassour, M.; Levin, J.Z.; Thompson, D.A.; Amit, I.; Adiconis, X.; Fan, L.; Raychowdhury, R.; Zeng, Q.; et al. Full-length transcriptome assembly from RNA-Seq data without a reference genome. Nat. Biotechnol. 2011, 29, 644. [CrossRef] [PubMed]

26. Wu, H.; Ma, Y.; Chen, T.; Wang, M.; Wang, X. PsRobot: A web-based plant small RNA meta-analysis toolbox. Nucleic Acids Res. 2012, 40, W22-W28. [CrossRef]

27. Benjamini, Y.; Yekutieli, D. The control of the false discovery rate in multiple testing under dependency. Ann. Stat. 2001, 29, 1165-1188.

28. Boyle, E.I.; Weng, S.; Gollub, J.; Jin, H.; Botstein, D.; Cherry, J.M.; Sherlock, G. GO::TermFinder-open source software for accessing Gene Ontology information and finding significantly enriched Gene Ontology terms associated with a list of genes. Bioinformatics 2004, 20, 3710-3715. [CrossRef] [PubMed]

29. Nakayama, H.; Nakayama, N.; Seiki, S.; Kojima, M.; Sakakibara, H.; Sinha, N.; Kimura, S. Regulation of the KNOX-GA gene module induces heterophyllic alteration in North American lake cress. Plant Cell 2014, 26, 4733-4748. [CrossRef] [PubMed]

30. Rieu, I.; Ruiz-Rivero, O.; Fernandez-Garcia, N.; Griffiths, J.; Powers, S.J.; Gong, F.; Linhartova, T.; Eriksson, S.; Nilsson, O.; Thomas, S.G.; et al. The gibberellin biosynthetic genes AtGA20ox1 and AtGA20ox2 act, partially redundantly, to promote growth and development throughout the Arabidopsis life cycle. Plant J. 2008, 53, 488-504. [CrossRef] [PubMed]

31. Křeček, P.; Skůpa, P.; Libus, J.; Naramoto, S.; Tejos, R.; Friml, J.; Zažímalová, E. The PIN-FORMED (PIN) protein family of auxin transporters. Genome Biol. 2009, 10, 249. [CrossRef] [PubMed] 
32. Nishimura, C.; Ohashi, Y.; Sato, S.; Kato, T.; Tabata, S.; Ueguchi, C. Histidine kinase homologs that act as cytokinin receptors possess overlapping functions in the regulation of shoot and root growth in Arabidopsis. Plant Cell 2004, 16, 1365-1377. [CrossRef] [PubMed]

33. Hake, S.; Smith, H.M.; Holtan, H.; Magnani, E.; Mele, G.; Ramirez, J. The role of knox genes in plant development. Annu. Rev. Cell Dev. Biol. 2004, 20, 125-151. [CrossRef] [PubMed]

34. Rast-Somssich, M.I.; Broholm, S.; Jenkins, H.; Canales, C.; Vlad, D.; Kwantes, M.; Bilsborough, G.; Dello, I.R.; Ewing, R.M.; Laufs, P. Alternate wiring of a KNOXI genetic network underlies differences in leaf development of Arabidopsis thaliana and Cardamine hirsuta. Gene Dev. 2015, 29, 2391-2404. [CrossRef] [PubMed]

35. Nikovics, K.; Blein, T.; Peaucelle, A.; Ishida, T.; Morin, H.; Aida, M.; Laufs, P. The balance between the MIR164A and CUC2 genes controls leaf margin serration in Arabidopsis. Plant Cell 2006, 18, 2929-2945. [CrossRef] [PubMed]

36. Blein, T.; Pulido, A.; Vialette-Guiraud, A.; Nikovics, K.; Morin, H.; Hay, A.; Johansen, I.E.; Tsiantis, M.; Laufs, P. A conserved molecular framework for compound leaf development. Science 2008, 322, 1835-1839. [CrossRef] [PubMed]

37. Poethig, R.S.; Sussex, I.M. The cellular parameters of leaf development in tobacco: A clonal analysis. Planta 1985, 165, 170-184. [CrossRef] [PubMed]

38. Aloni, R. Differentiation of vascular tissues. Annu. Rev. Plant Physiol. 2003, 38, 179-204. [CrossRef]

39. Hagemann, W.; Gleissberg, S. Organogenetic capacity of leaves: The significance of marginal blastozones in angiosperms. Plant Syst. Evol. 1996, 199, 121-152. [CrossRef]

40. Bergmann, D.C.; Sack, F.D. Stomatal development. Annu. Rev. Plant Biol. 2007, 58, 163-181. [CrossRef] [PubMed]

41. Crawford, B.C.; Nath, U.; Carpenter, R.; Coen, E.S. CINCINNATA controls both cell differentiation and growth in petal lobes and leaves of Antirrhinum. Plant Physiol. 2004, 135, 244-253. [CrossRef] [PubMed]

42. Hamant, O.; Pautot, V. Plant development: A TALE story. C. R. Biol. 2010, 333, 371-381. [CrossRef] [PubMed]

43. Venglat, S.P.; Dumonceaux, T.; Rozwadowski, K.; Parnell, L.; Babic, V.; Keller, W.; Martienssen, R.; Selvaraj, G.; Datla, R. The homeobox gene BREVIPEDICELLUS is a key regulator of inflorescence architecture in Arabidopsis. Proc. Natl. Acad. Sci. USA 2002, 99, 4730-4735. [CrossRef] [PubMed]

44. Scanlon, M.J. The polar auxin transport inhibitor N-1-Naphthylphthalamic acid disrupts leaf initiation, KNOX protein regulation, and formation of leaf margins in maize. Plant Physiol. 2003, 133, 597-605. [CrossRef] [PubMed]

45. Zhao, Z.; Andersen, S.U.; Ljung, K.; Dolezal, K.; Miotk, A.; Schultheiss, S.J.; Lohmann, J.U. Hormonal control of the shoot stem-cell niche. Nature 2010, 465, 1089-1092. [CrossRef] [PubMed]

46. Maugarny, A.; Gonçalves, B.; Arnaud, N.; Laufs, P. CUC transcription factors: To the meristem and Beyond; Elsevier: Amsterdam, The Netherlands, 2015; pp. 229-247. ISBN 978-0-12-800854-6.

47. Heisler, M.G.; Ohno, C.; Das, P.; Sieber, P.; Reddy, G.V.; Long, J.A.; Meyerowitz, E.M. Patterns of auxin transport and gene expression during primordium development revealed by live imaging of the Arabidopsis inflorescence meristem. Curr. Biol. 2005, 15, 1899-1911. [CrossRef] [PubMed]

48. Abley, K.; Sauret-Güeto, S.; Marée, A.F.; Coen, E. Formation of polarity convergences underlying shoot outgrowths. eLife 2016, 5, e18165. [CrossRef] [PubMed]

49. Benjamins, R.; Scheres, B. Auxin: The looping star in plant development. Annu. Rev. Plant Biol. 2008, 59, 443-465. [CrossRef] [PubMed]

(C) 2018 by the authors. Licensee MDPI, Basel, Switzerland. This article is an open access article distributed under the terms and conditions of the Creative Commons Attribution (CC BY) license (http:/ / creativecommons.org/licenses/by/4.0/). 